\title{
Using Authentic Materials in EFL Classes in Benin for Communicative Competence
}

\author{
Estelle Bankole-Minaflinou* \\ Department of English, University of Abomey-Calavi, Benin
}

*Corresponding Author: Estelle Bankole-Minaflinou, Department of English, University of AbomeyCalavi, Benin

\begin{abstract}
This research paper sets out to explore the use of authentic materials to promote EFL communicative competence in secondary schools in Benin. Various textbooks have the potential to provide the necessary language input if they include genuine examples of language use as opposed to specifically written language for teaching purposes. To reach its goal the present study has first introduced the concept of what is defined as authentic materials and presents various perceptions of researchers and their usefulness in EFL classes. Data were collected through questionnaire and language test from two categories of teachers and students; one using a series of textbooks containing many authentic materials and the other group, exposed to the conventional pedagogic materials. The data analysis through the SPSS (Statistical Package for Social science) tools revealed that the experimental group presents more ability for communicative competence than the control group. In other words, teaching EFL in Benin using authentic materials (AM) proved to have significant effect on improving Beninese learners' communicative competence.
\end{abstract}

Keywords: Authentic materials (AM); communicative competence; EFL students; conventional materials; contrived materials

\section{INTRODUCTION}

Learning a foreign language and being able to use it for communicative purposes require more than the rote learning of vocabularies and grammatical structures. In order to use efficiently this international language which is English and to acquire the capability to communicate effectively in it, Beninese English learners need to improve their communicative competence. In general, communicative competence can be defined as the learner's ability to apply and use grammatical rules, to form correct utterances and to know how to use them appropriately (Brown, 2007). In other words, the basic idea of communicative competence remains the ability to use language appropriately, both receptively and productively in real life situations. For this to be possible, various sources of input are considered among which authentic language input through AM. Morly and Guariento (2001) claim that the purpose of using AM is to prepare students for their social lives. In other words, they are used in order to bridge the language gap between classroom knowledge and real life.

In Benin, different types of textbooks have been used to expose learners to language input supposed to help them achieve communicative competence. The sad reality is that after the completion of the seven years in secondary school, their standard of English proficiency remains very low. This may be due to the methods of language teaching and the learning environment which apparently seem not to be conducive to a rewarding language learning.

To deal with this situation, one solution may be that teachers must simulate real-world situations in the classroom (Stern, 1981) on one hand and make use of authentic materials as supplementary materials to support the recommended textbooks on the other hand. Examples of such materials include newspapers, magazines, TV programs, radio talks, menus, brochures, comics, novels, short stories, weather forecasts, and recipes (Hedge, 2000). Despite a growing awareness about the effective use of these resources in EFL contexts, Beninese EFL teachers' attitudes about the issue seem not to have received so far enough attention for communicative competence promotion. Secondly, this paper was conducted to investigate the effect of using AM on students' communicative competence. So far, no empirical research has been carried out to illuminate EFL teachers to know exactly the rationale 
behind the use of AM and be able to use them confidently for students' communicative competence so as to contribute to their spread as a strategic teaching source in EFL teaching in Benin.

Hopefully, this paper aims to contribute to the literature on material development so that researchenlightened choices can be made. The findings might help syllabus designers and course planners to design up-to-date course syllabus and teaching methodologies that focus on AM in order to give EFL teachers an extra capacity to play their roles more effectively and foster learners' language competence.

So, the objectives of the present study are to examine the perceptions and attitudes of Beninese teachers towards the use of AM, their significance as EFL resources so as to promote learners' language competence.

Therefore, the following research questions are presented:

1. What are Beninese EFL teachers' perceptions and attitudes towards the significance and use of AM?

2. What are the effects of the use of AM on students' language communicative competence?

\section{LITERATURE REVIEW}

\subsection{Background to the Study}

English is taught as a foreign language in Benin. Despite the fact that students study it as a subject over several years, it does not have applications beyond school settings. As they do not have enough exposure to the language, their English skills remain mostly poor. Various teaching materials are considered to be essential components in language learning and sources of input in and outside the classroom setting. In Benin, two series of textbooks are in use across the seven years of secondary school: Document d' Accompagnement (DA) and Go for English (GE). A minute examination of the DA series from the first to the fourth grade level shows that real world tasks capable of molding learners into potentials communicators are minimized across the four grades level textbooks. Overall, 09 instances of authentic discourses (real conversations + authentic texts) are identified and recorded against 137 unauthentic discourse (scripted dialogs+ unauthentic texts). The second series of the three upper proficiency level textbooks of Go for English features 67 instances of authentic discourses against 96 instances of unauthentic discourses. There is another series of textbooks called Top in English mostly used in some private schools across the seven secondary school years which features a total 96 examples of authentic discourses against 26 of unauthentic materials

In sum, the number of task-based activities across the seven proficiency level text books in state schools, remains extremely low. The omission of such activities in the classroom could be justified by the disregard often shown for real world issues in English teaching pedagogy in Benin. Graham, H. (2011) observed that: "Authentic texts and tasks draw upon more realistic models of language use and leave learners better prepared for life outside the class. "(p.192)There is therefore, an urgent need to cater for language competence in real life. Many researchers have proposed different definitions for pragmatic competence. In general, communicative competence can be defined as the learner's ability to apply and use grammatical rules, to form correct utterances appropriately. According to Brown, (2007) the basic idea of communicative competence remains the ability to understand, construct and transfer meanings that is to use language appropriately, both receptively and productively, in social situations. Kasper and Rose, (1996) contend that the main purpose of pragmatic competence is to be able to communicate effectively. Based on the above explanations of pragmatic competence, it is true that many EFL learners in Benin have a good knowledge of grammatical structures and lexis but they come across serious difficulties when they engage in real communication because of pragmatic failure. Omaggio Hadley, (1993) states that one of the most important principles of communicative language knowledge or instruction is using authentic materials or instructions. A scrutiny at the previous studies will highlight more the issue.

\subsection{Review of the Previous Studies}

The use of authentic language input through AM in EFL learning has a long history. Henry Sweet (1899, cited in Gilmore, 2007) was one of the pioneers who showed in his books that the use of authentic texts has more advantages for learners than the contrived materials. In the seventies with the advent of the introduction of communicative approach, the idea of using AM regains prominence. 
The positive impact of authentic texts on learners who were exposed to them was revealed by many empirical studies. For example, Than a jaro, (2000) and Miller, (2005) showed that aural language of the students received improvement when treated with AM. This was confirmed by another of their study with four adults of American universities which showed an increase of their listening comprehension due to exposure to AM. The study of Young, (1999) reported also better scores with the use of AM in comparison with the use of textbooks. Moreover, Gilmore, (2007) made the comparison of the effectiveness of AM with textbook materials to investigate the learners' communicative competence in a Japanese university. The results showed significant improvements in the experimental group than the control group. Chavez, (1998) then concluded that "the authentic input allowed learners to focus on a wider range of materials and it has beneficial effects on the learners' development of communicative competence". Sarapli, (2011) carried out an investigation about the application of online technologies to AM for the opportunities they provide. The results showed that using technology to teach AM could not only reduce language student anxiety inherent to any language learning and more importantly to exposure to authentic foreign language, but it can prove to be very engaging, appropriate and affordable.

These various studies conducted in different contexts have revealed the effectiveness of AM in many ways. The more are students exposed to the language used in real life, the more are their language skills enhanced and upgraded. What is undeniable is that the use of AM in EFL teaching offers many advantages. In teaching grammar, they help students to recognize the samples of English used by its native speakers and help students to be more communicative in classroom activities [Wang \& Sachs (2011)]. Peacock, (1997) cited in Richard, (2001) listed some advantages. They have a positive effect on students' motivation; they provide authentic cultural information about the target culture; they provide exposure to real language; they relate more closely to students' needs and finally they support a more creative approach to teaching. According to this approach, learners construct "their own knowledge by testing ideas and approaches based on their prior knowledge and experience, applying these to a new situation, and integrating the new knowledge gained with pre-existing intellectual constructs" (Brinner, 1999, p.2). This constructivist learning approach is the foundation of the Competency-Based Approach being implemented in Benin for some years now. It stipulates that each learner should take responsibility for his/her own learning, interacting with his or her environment rather than being passive receivers of information to be transmitted to him/her. The essence in constructivist learning environment is that students should interact with authentic activities and materials representing real world.

However, Breen, $(1985$, p.350) discovers that there are four types of authenticity within language teaching. These types are according to him in continual interrelationship with one another during any language lesson. These types include:

$>$ Authenticity of the texts which may use as input data for learners;

$>$ Authenticity of the learners' own interpretations of such texts;

$>$ Authenticity of task conducive to language learning;

$>$ Authenticity of the actual social situations of the language classroom.

On the other hand, many researchers went further to identify some significant disadvantages in using AM in comparison with traditional textbooks. Martinez cited in Berardo, (2006) is of the view that AM show too cultural biased though he is aware that good knowledge of cultural background is needed to understand such texts. Another shortcoming spotted is that lower level students may find the understanding of such materials difficult because of the complexity of the language and the mixture of various structures. This alone can lead to frustration, confusion and de-motivation. Richard, (2001) argued that using AM is a burden for teachers because setting the materials to fit learning objectives can be time-consuming and disorientating, mainly for an inexperienced young teacher. Another aggravating factor is when the only real purpose for students to learn the language is for examination success.

Nonetheless, the pedagogical value of authentic language materials cannot wisely be rejected. Therefore, researchers like Bahrani, \& Tam (2013) listed some important criteria for the selection of AM: 
1. The students' language proficiency should be considered;

2. Choose stories that are relevant to students' lives;

3. Ask the students about their preferences regarding different types of audiovisual programs;

4. Choose stories that motivate the students;

5. Use various broadcasts that provide exposure to various accents and cultures;

6. Choose stories that are proficiency-level appropriate; political and science related stories are often too difficult for many students to understand;

7. Use stories that lend themselves to many learning activities.

However, there are different types of AM. Genhard, (1996) classified AM into three categories as follows:

* Authentic listening materials, such as radio news, cartoons, songs, etc.

* Authentic visual materials: street signs, magazines and newspapers pictures, post cards, etc.

* Authentic printed materials: sports reports, newspapers, restaurant menus, train tickets etc.

Many other sources of AM can be used in the classroom but the most common materials are: newspapers, magazines, TV programs, movies, Video/DVD, rhymes and poems, pictures, charts, diagrams, advertisements, realia such as airline tickets, hotel information, leaflets, posters, instructional manuals, telephone books, menus, maps, post cards, etc. From a more practical point of view, the internet is a modern day reality most teachers and students use today giving access to endless amounts of many different types of materials [Ellis, (1996)].

To come to the heart of the study a down-to-earth scrutiny is needed to shed light on the issue through investigation.

\section{MeTHOD}

\subsection{Design of the Study}

To raise the awareness of Beninese EFL teachers to use AM as contributory factors to their students' language competence, the current study is exploratory in nature. For this purpose, the design of the current study is quantitative and qualitative in methods using experimental type of research which allows subjects to be divided into two or more groups: control and experimental groups (Mayer, 2005).Five- point Likert- scale questionnaire ranging from 'Strongly disagree', 'Disagree', 'Uncertain', 'Agree', to 'Strongly agree' and an adapted Solution Placement Test were developed as measuring instruments. Interviews were also held, conducted by the researcher herself.

\subsection{Participants}

To collect the required data for the research questions, ten (10) EFL teachers, teaching in state and private schools, both the conventional (DA) and AM textbooks (TE)across the seven years proficiency level (first and second cycle) were purposively sampled to fill in the researcher-designed Likert scale questionnaire. The rationale behind this choice is that they are the only teachers who know better both types of textbooks and can give reliable answers about their use.

Two categories of students were also purposively selected. The first category is made up of ten (10) fourth year secondary school students, randomly selected and exposed to the series of textbooks called 'Document d'Accompagnement'(DA)which are contrived locally-made materials. This category of students serves as the control group. The second category is ten (10) private school EFL students, randomly selected, of the same level and exposed to the series of another locally-made textbooks called Top in English (TE) that features many AM. This category is considered as the experimental group. These two types of students have been studying English for at least four years with four hours of English per week and exposed to the same national certificated summative exam called BEPC.

\subsection{Instrumentation}

\subsubsection{Questionnaire}

The questionnaire to teachers were distributed to ten (10) participants to elicit their perceptions and attitudes about the use AM in the two different series of textbooks. Crookes and Schmidt (1991, p.51) 
described the following merits of the survey design by opining that it: "......generalizes about the entire population by collecting data from the small portion of that population. It reveals the characteristics of the communities and institutions in a relatively unbiased and scientifically rigorous manner. 'In spite of some negligible weaknesses, this method is thought to be the most commonly used technique to collect data in a quantitative paradigm.

\subsubsection{Teachers' Questionnaire}

This questionnaire is made up of ten Likert-scale items ranging from 'Strongly disagree', 'Disagree', 'Uncertain', 'Agree', to 'Strongly agree' and dealing with: their preference between DA and TE as teaching materials; AM textbooks for students' knowledge; increase of proficiency than traditional textbooks; AM and cultural conflicts; AM and cultural barriers; AM and difficulty of selection; time constraints; starting level and criteria for selection.

\subsubsection{Solutions Placement Test (SPT)}

The version of SPT used for the purpose of the present study is an adapted one made up of four items: (1) a grammar and vocabulary test with 20 completion items; (2) a reading test with 10 comprehension items (05 'True \&False' and 05 multiple choice questions); (3) a writing test made up of an E-mail message to a friend; (4) a speaking assessment test made up of 05 reasonably simple questions.

Questions or tasks were designed on the basis of representative illustration of facts that test takers are familiar with so as to enable them easily understand what is asked of them and not to lack ideas for answer. To satisfy the construct validation of this test, the researcher made sure that the questions or tasks match its objectives that is testing learners' communicative language competence. Moreover, she was helped in giving and scoring the test by two assistants still teaching at secondary school level. This is how the scoring features:

(1) Grammar \& Vocabulary: 40 points (2 x20 items)

(2) Reading: 20 points ( $2 \times 10$ items)

(3) Writing: 20 points ( $2 \times 10$ items)

(4) Speaking: 20 points ( $4 \times 5$ items)

$$
\text { Total }=100 \text { points }
$$

Each category of students took exactly the same test. The average grade consists of the computation of the four items and categorized as follows:

Poor: $20-40$ points

Average: $40-60$ points

Good: $60-80$ points

Very good: 80 plus

\subsection{Interview}

The aim of the qualitative data analysis is to achieve a thorough understanding of the target phenomenon. The choice of qualitative interviews was made since it is "a uniquely sensitive and powerful method for capturing the lived experiences and lived meanings of the subjects' everyday world”. (Kwale, 2007, p. 11).

The current study has also used qualitative techniques for data collection. Three semi-structured interview questions designed by the researcher herself were asked to two randomly selected students from both types of students including two classroom teachers, to explore their perceptions, opinions and attitudes, in a face-to-face individual audio-taped interview with the researcher. Each of them voiced his/her perceptions and attitudes about the current situation. Some questions, probes, prompts and intuitive questions were framed, based on the researcher's own experience as a teacher trainer. Each interview lasts ten to twenty minutes. This open-ended interview method was designed to minimize the limitations of the self-completion questionnaire method. The teachers' questions are as follows: what are your perceptions and attitudes about the use of both types of textbooks (DA and TE) 
in your classes? (2) What do you think of their effectiveness to promote your students' language competence?

As for students, the researcher made sure that the interviewed students had a clear idea of what is meant by 'authentic materials' before she started the interview. The questions were: (1) What do you think of your textbook as far AM are concerned? (2) Do you think that your textbook can really help you develop communicative competence?

The interview with students was carried out in French because of the low standard in English which makes communication not easy.

\subsection{Data Collection and Analysis Procedure}

The data were collected through a Likert-scale questionnaire and an adapted OPT instrument. The first one had been handedto teachers for completionfor a week. For the second one, the researcher assisted by two secondary school teachers conducted the test which was administered toboth categories of students (control and experimental group) in a face-to-face environment.

The data collected were entered on and analyzed with the help of a computer software program: the Statistical Package for Social Sciences (SPSS). Data were analyzed with the help of frequencies, percentages, mean and standard deviation. To analyze the data of this survey, the inductive analysis strategy was used through description, analysis and interpretation. All the data have highlighted the twomain research questions.

\subsection{Validity and Reliability of the Instruments}

Ebel, (1972, p.78) claims that face validity is secured if the items appear to be measuring what it is supposed to measure. White and Gunstone (1992, p.177) state that "reliability refers to the consistency of the judgment that follows from the use of a test". In other words, a questionnaire for example is reliable when it yields the same results over a given time. In order to ensure the validity and reliability of these instruments, their first versions were exposed to local experts in the fields of linguistics and methodology of teaching EFL and inspectors. They were kindly requested to judge the relevance and suitability of the current study instruments. The outcome is that some items were added and some omitted for clarification and conciseness sake. Therefore, the reformulated final form of the questionnaire consists of ten items each and the Placement Test was also reviewed.

\section{Presentation and Discussion of Results}

The results of this study are presented in regard to the two research questions. They are presented, analyzed and interpreted.

\subsection{Presentation of Results}

\subsubsection{Teachers' Questionnaire Results}

The data generated through the participant teachers were analyzed to answer the research questions. Their perceptions about the use and effectiveness of AM to promote their students' language competence are presented and discussed. The following table shows the results.

Table1: Teachers' perceptions about the use and effectiveness of AM

\begin{tabular}{|l|l|l|l|l|l|}
\hline & N & Minimum & Maximum & Mean & Std. Deviation \\
\hline Preference between DA \& TE. & 10 & 1 & 2 & 1.20 &, 422 \\
\hline AM as supplement & 10 & 4 & 5 & 4.10 &, 316 \\
\hline AM increase knowledge & 10 & 4 & 5 & 4.20 &, 422 \\
\hline AM increase proficiency & 10 & 1 & 5 & 3.40 & 1,713 \\
\hline AM cause cultural conflicts & 10 & 2 & 4 & 3.00 &, 816 \\
\hline AM as cultural barriers & 10 & 2 & 4 & 3.10 &, 876 \\
\hline AM difficulty in selection of materials & 10 & 3 & 5 & 4.40 &, 699 \\
\hline AM time- consuming & 10 & 2 & 5 & 3.80 & 1,033 \\
\hline AM start any level & 10 & 1 & 4 & 2.50 & 1,354 \\
\hline AM criteria of selection & 10 & 3 & 5 & 4.50 &, 850 \\
\hline
\end{tabular}

Based on the descriptive statistics all the ten variables are presented in table 1 above with their mean scores, minimum, maximum and standard deviation. As indicated in the table, among the different 
mean scores of the ten variables as regard teachers' perceptions about the use and effectiveness of $\mathrm{AM}$, the following variables scored very high: 'criteria of selection' (4.50); 'difficulty in selection of materials (4.40); 'AM increase knowledge'(4.20);'AM as supplementary materials' (4.10). This proves that these teachers are aware of the effectiveness of AM having used both types in different classes. The other variables also show high scores: time-consuming in their use (3.80); 'AM increase students' proficiency more than contrived textbooks materials'(3.40);overcome cultural barriers (3.10); AM can cause cultural conflicts that hinder comprehension'(3.00); 'AM can be used at any level'(2.50) . This shows that the respondent teachers not only supported the use of AM to stimulate the interest of Beninese students, but they have a balanced view about the issue. They are conscious of the advantages and even the constraints of using AM. The item which scored very low is 'any difference in using contrived textbooks and AM'. This may imply that the teachers are aware of the complementary roles of both input sources.

Apart from the three variables which have high standard deviation, 'AM increase proficiency' (1,713); AM can be started at any level $(1,354$ ) AM time- consuming $(1,033)$ which mean that these views are not harmoniously spread among these respondents, all the other seven items reflect the similarity in these teachers' perceptions about the use of AM.

\subsubsection{Students' Tests Results}

Table2: Experimental Group Results

\begin{tabular}{|c|l|l|l|l|l|}
\hline language competence & \multicolumn{1}{|c|}{ N } & Minimum & Maximum & Mean & Std. Deviation \\
\hline & 10 & 2 & 4 & 2.70 &, 675 \\
\hline & 10 & & & & \\
\hline
\end{tabular}

Table3: Control Group Results

\begin{tabular}{|c|c|c|c|c|c|}
\hline language competence & $\mathbf{N}$ & Minimum & Maximum & Mean & Std. Deviation \\
\hline & 10 & 1 & 3 & 1.70 &, 675 \\
\hline
\end{tabular}

The data in both tables show a mean of 1.70 for the control group and a mean of 2.70 for the experimental group. The mean scores of the experimental group are higher than the control group's mean scores. This proves that there is a significant difference between the mean performance of the control group that is students exposed to contrived materials and the experimental group who are students exposed to 'Top in English'a series of materials made up of many AM.

However, the standard deviation of both groups is exactly the same and shows no difference. Therefore, the categorization of the language competence has been cross tabulated with each group status in the table and the bar graph below.

\begin{tabular}{|l|l|l|l|l|l|l|}
\hline \multicolumn{2}{|c|}{} & \multicolumn{4}{c|}{ language competence } & \multirow{2}{*}{ Total } \\
\cline { 3 - 7 } \multicolumn{2}{|c|}{ poor } & Average & Good & Very good & \\
\hline \multirow{2}{*}{ Status } & Experimental Group & 0 & 4 & 5 & 1 & 10 \\
\cline { 2 - 7 } & Control Group & 4 & 5 & 1 & 0 & 10 \\
\hline Total & 4 & 9 & 6 & 1 & 20 \\
\hline
\end{tabular}

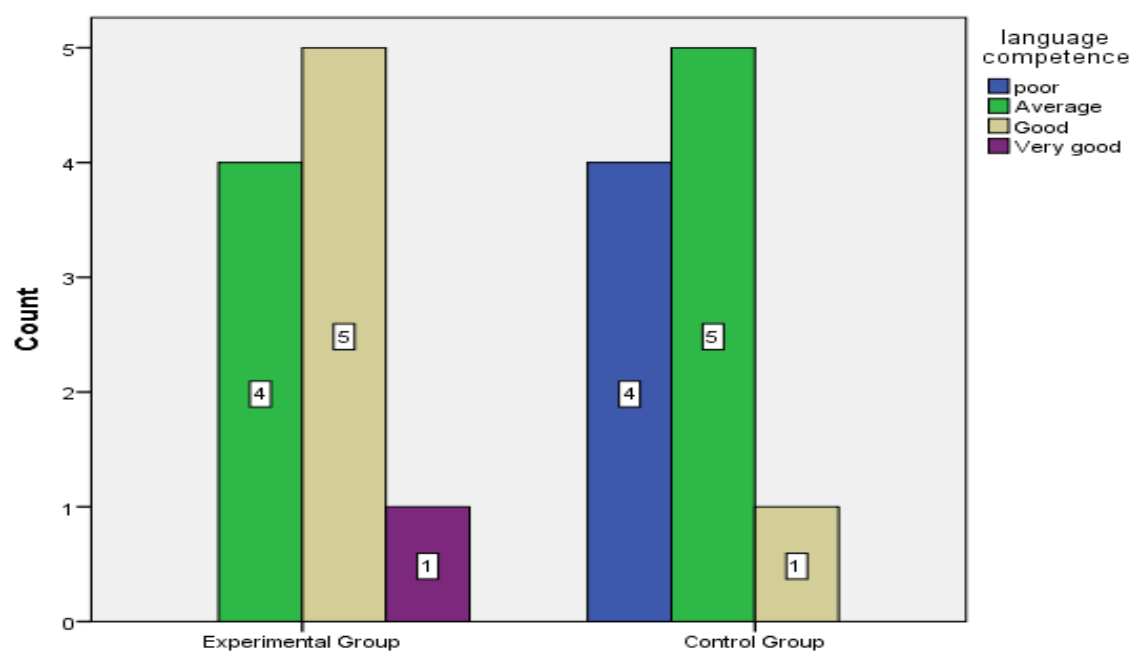


Both the table and figure above show that the experimental group that is those who were exposed to more AM presents no poor student against four (4) for the control group who uses contrived materials; five (5) 'average' against four (4) ; five (5) 'good' against one (1); one 'very good' against zero for the control group. Obviously, st0udents who were exposed to more AM did better in the test than those who use traditional textbooks.

\subsubsection{Results of both Teachers and Students' Interviews}

Teachers made the following reflections:

- Authentic materials or texts are beneficial to the language learning process;

- They have a positive effect on learner motivation for it provides excitement and fun;

- They are not easy to use if they are not included in the prescribed textbooks because of their unavailability in francophone countries;

- As they promote the development of practical life skills, there is more communication in class and so language competence can be expected;

- Appropriate training is needed to know how to exploit effectively AM for student language competence;

- What language level should be exposed to AM?

- Selecting materials is not an easy task.

This is one of the student' excerpt of the interview

"I do like authentic texts and tasks. We learn a lot from them for they

prepare us for real life. But some of them are difficult to decode even for our

teachers. they can improve our language proficiency but I don't know why

we are not doing well in English. Maybe what we need is real

linguistic exposure in an English speaking country." (My own translation)

\subsection{Discussion of the Results}

The main purpose of the present study is to investigate the use and effectiveness of AM and their potential impact on students to develop language competence. Therefore, the present discussion will hinge around the two research questions which enquired about Beninese teachers' perceptions towards the significance and use of AM and how far they can contribute to students' language competence.

\subsubsection{Teachers' Perceptions about the Use and Effectiveness of AM}

The results and the analysis of the data of the respondent teachers reveal that most of them have similar positive and balanced views about the use and effectiveness of AM.

The very items that scored very high are the following: AM increase students' knowledge and enhance their language proficiency. So, the positive effect of AM on language learning is confirmed. It can then be inferred that textbooks using a lot of AM stand the chance of helping the promotion of the development of skills necessary for linguistic competence. This is in line with Chavez, (1998) and Scrivener, (1996) cited in the literature review who believe that AM make possible for language learners to absorb real life examples of language used by its native and can in turn produce the same or approximately near native use of the language. What is evident is that when a teacher uses these types of materials, not only an atmosphere of excitement prevails in the class, but boredom that characterizes many EFL classes and produces disruptive behavior fades away. In fact, exposure to AM stands more chance to help EFL learners acquire an effective competence in a foreign language context such as Benin and as a result, bridge the gap between the classroom knowledge and their participation in the real world.

If many of the respondent teachers identified problems in materials selection, it is due to the foreign language environment compounded by lack of appropriate English materials such as for instance greeting cards, report cards, TV guides, food labels, magazines, newspapers etc. But the problem in 
Beninese education is that more than half of the teaching force is untrained and this is a real challenge that needs prompt repair. Otherwise, it would be difficult for a classroom teacher to know the suitability of a material content, the exploitability and readability of a material and as a result, not be able for example to use change-of-address forms, job application forms, menus, voice mail messages, radio programs, videos etc.AM might also be integrated into language elements and skills classes, where students can increase their knowledge of grammatical and lexical items as they occur in their original contexts and not as isolated entities. In fact, the criteria for the selection of materials should take account of the needs, interests, age, gender and the level of the students: beginners, intermediate or advanced students. Therefore, the qualitative results of the survey, the interview reveals that teachers care much about which of the two types of the students (first and second cycle) should exclusively be exposed to AM. One of the interviewed teachers even went further to say that he prefers the current curriculum which allows first cycle students to use contrived textbooks and reserves AM text books to mature students. The reality is that though AM can overcome cultural barriers, if care is not taken, it can also cause cultural conflicts that hinder comprehension. There is then need for an experienced teacher to use his ability and know-how to select appropriate materials to avoid such a handicap in the use of AM. No wonder that some researchers contradict the view that AM have positive effects on language learning. Kilickaya, (2004) for instance, claimed that authentic texts stay in the way of the teaching of vocabulary, ,structures, language functions, content, thereby causing a burden for the classroom teacher. Another of his contrasting view is the use of AM at lower level. He believes that this can cause students' frustration and demotivation because of the complexity of lexical items and structures used in most of AM. McNeil, (1994) and Miller, (2005) mentioned challenges regarding access to AM, their cost and the time required to find appropriate one and being able to design suitable tasks. These are the very challenges Beninese teachers, mainly untrained and inexperienced ones have been struggling hard to overcome. Hence, the need for nation-wide training many respondent teachers advocated during the interview sessions.

The researcher is of the views that even at lower levels AM can be used to supplement contrived materials as the students' results revealed. Moreover, as most foreign language learners are ambitious about drawing near native speakers' proficiency, it seems rewarding to add AM to their textbooks in different educational contexts. The type of activities which were heavily favored by these learners are games and other group activities where they can collaborate and feel a sense of security and which can raise their motivation. Because of the positive effects of AM, confirmed by many researchers, Day and Bamford, (1998) are of the supporting view that even simplified texts should be judged in terms of whether they have the natural qualities of authenticity or not.

\subsubsection{Authentic Materials Contribution to Language Competence}

The data from both types of students reveal that the experimental group made of students exposed to AM present better language competence than the control group made up of students taught with contrived materials. In other words, Beninese EFL learners who were exposed to more AM outperformed those learners who were taught English through pedagogic and traditional materials. These results could be added to the results of other studies which confirm not only the positive effects of AM to language learning, but more importantly on students' performance, comfort and selfconfidence. The students' interview results show that most of the students preferred using AM because they deal with outside world and real language and make them familiar with the culture of the target language and also increase their motivation. Furthermore, the answers of the respondent teachers reveal that AM have positive impact on students' attitudes and motivation. This implies that these language instructors could promote positive attitudes of the Beninese students toward language learning by providing materials and tasks that satisfy their needs and interest

The findings of the present research may be beneficial for materials and curriculum developers in designing and preparing AM that are more adaptable with communicative and learner-centered approaches. In fact, the Competency-Based Approach (CBA) being implemented in Benin for some years now is a constructivist approach, the essence of which is providing the learners with a learning environment where students should interact with authentic activities and materials representing real life experience, using cooperative learning and communicating with friends.

It seems wise to advice the use of both contrived and AM textbooks after light having been shed on the rationale about each of them. In the first cycle, the contrived materials can be supplemented by 
authentic texts chosen for students' communicative competence. For second cycle students, the use of the AM textbooks needs to benefit from communicative tasks which can be achieved by the mixture of AM with communicative activities.

\section{STRATEGIES FOR IMPLEMENTATION}

Based on the findings of this study, the following strategies may be considered useful to improve Beninese students' communicative language competence. In fact, there is need to implement some strategies that will help the classroom teacher use his/her teaching skills to satisfy students' needs and interests which are learning English for communication competence. The following, adapted from Bahrani \& Tam (2013) may be of help.

- Offer students a choice in the content of the materials to present in class by taking an inventory of their interests.

- Get feedback from the students regarding their comfort level on the various four skills assignments, processes, and procedures used in conjunction with the stories or tasks.

- Ask students regularly about their feelings about activities in class. Give them a formal feedback form to fill out and ask them informally to voice their viewpoints.

- All four skills activities should include opportunities for students to play an active role in their own learning.

A sample of such activities can be the following adapted from Chou (2018).

\subsection{Job Application}

"Because many companies use an online application form to screen their candidates, the teacher can have a class lesson set aside to have students fill out online job searcher profiles. The process emulates that of an online job application because students will be asked to fill out basic information about themselves, upload a resume and even submit a profile photo which is a natural way to briefly introduce themselves to the hiring world".

The main benefits of using these kinds of activities are clear. Not only will students' confidence and experience in using 'real' language be boosted, but they will encounter words and constructions that they would probably never see in formal materials.

Moreover, AM can provide realistic context for role -play, letter or report-writing, stimulate debates, provide information for a project or presentation or practice the skills of describing, explaining, instructing and exchanging information (Ellis, 2013).

There should also be a rejuvenation of various radio and television programs for the teaching of English language to provide Beninese students with authentic sources for language skills development. A clear and sustainable policy on the integration of media in education supported by a media campaign should be started with the assistance of state and private televisions and FM radios about the merits of learning English using other sources other than the prescribed textbooks.

Based on the outcome of the present study, possible areas for future researches may be to investigate the effectiveness of AM to improve different skills: writing, listening, reading and speaking. Because of the limitation of the present study - conducted with a limited number of teachers and students- a replication of the study with more participants and authentic exposure with pre and post test results is suggested to obtain more reliable results that would make its generalization easier. Participants' gender differences, student motivation and attitudes can also be regarded as variables to investigate in future studies. The effect of AM on ESP students language learning in technical schools can also be investigated as they constitute so far an unexplored field.

\section{CONCLUSION}

This study has shed light on teachers' perceptions about the use of AM and their potentiality to improve EFL learners' language competence in Benin. The quantitative and qualitative results confirm that both sample groups of teachers and students represented by the cohort of this study provided congruent views on the significance of AM in teaching secondary school students for communicative competence. 
What is undeniable today is that many researchers have positive views about the use of $\mathrm{AM}$ in EFL/ESL classrooms and despite some apparent disadvantages, the pros of using AM in Beninese EFL classrooms outweigh its cons. As a result, its proper implementation in Beninese EFL classes may help students get the exposure of real life discourse that occurs in the natural interaction outside the classroom.

It has then been suggested that AM can be safely used at every level but as supplementary materials in lower level classes. Nevertheless, they should be chosen in agreement with the criteria of suitability of content, exploitability and readability of the materials. More importantly, the teachers should take account of the students' needs and interests, their level, their gender, and the materials to be used in designing effective and suitable tasks that are in line with the course objectives.

\section{REFERENCES}

[1] Bahrani, T. \& Tam, S.S. (2013). Authentic Language Input for Language Learning in EFL/ESL Contexts. The International Journal of Language Learning and Applied Linguistics World, 3 (2), 67-72.

[2] Berardo, S. (2006). The Use of Authentic Materials in the Teaching of Reading. The Reading Matrix, 6 (2), 60-69.

[3] Breen, M. (1985). Authenticity in the language classroom. Applied Linguistics, 6, 60-70.

[4] Brinner, J., (1999). Postmodernism and Constructivism. Retrieved from http://curriculum.casltatelaedu./ faculty/psparks/theorist/htm.

[5] Brown, H.D. (2007). Principles of language learning and teaching. (5 ${ }^{\text {th }}$ ed.). San Franscisco : Pearson Education.

[6] Chavez, M. T. (1998). Learner's perspectives on authenticity. IRAL, 36 (4), 277-306.

[7] Chou, E. (2018). 4 Creative Ways to Use Authentic Materials for teaching English. Fluent U English educator Blog. Retrieved from https://www.fluentu.com/blog/educator-english/ authentic-materials-forteaching-english/.

[8] Crookes, G. \& Schmidt, R. W. (1991). Motivation: Reopening the research agenda. Language Learning, 41, 469- 512.

[9] Day, R. D. \&Bamford, J. (1998). The Cult of Authenticity and the Myth of Simplification. In Extensive reading in the Second language classroom (pp.53-63).Cambridge: Cambridge University Press.

[10] Ebel, R. L. (1972).Essentials of Educational Measurement. Englewood Cliffs N. J. Prentice Hall.

[11] Ellis, R. (2013). Task-based Language Learning and Teaching. Oxford: Oxford University Press.

[12] Genhard, J.G. (1996). Teaching English as a Foreign language: a teacher self-development and methodology. Ann Arbor: The University of Michigan Press.

[13] Gilmore, A. (2007). Authentic materials and authenticity in foreign language learning. Language teaching. 40: $97-118$.

[14] Graham, M S. (2015). Authentic Materials: A Motivational Tool for the EFL Classroom? Education and Linguistics Research. Vol. 1, N. 2, 100-119

[15] Hedge, T. (2000). Teaching and learning in the language classroom. Oxford: Oxford University Press.

[16] Kasper, G. \& Rose, K. R. (2002). Pragmatic Development in a Second Language. Oxford: Blackwell.

[17] Kilickaya, F. (2004). Authentic Materials and Cultural content in EFL Classrooms. The Internet EFL Journal, 10 (7), 105-120.

[18] Kwale, S. (2007)Doing interviews. London: Sage.

[19] McNeil, A. (1994). What makes Authentic Materials different? The Case of English Language Materials for Educational Television. Paper presented at the Annual International Language in Education Conference. Hong Kong.

[20] Mayer, R. E. (2015).The Failure of Educational Research to Impact Educational Practice: Javanovich University Press.

[21] Miller, M. (2005). Improving aural comprehension skills in EFL, using authentic materials: an experiment with university students in Nigata, Japan. Unpublished master's thesis. University of Surrey, Guildford, $U K$.

[22] Morley, J. \& Guariento, W. (2001). Text and Task Authenticity in the EFL Classroom. ELT Journal, 55 (4), 347-353.

[23] Omaggio Hadley, A. (1993). Teaching language in context. Boston: Heinle \& Heinle.

[24] Peacock, M. (1997). The effect of authentic materials on the motivation of EFL learners. ELT Journal, 51 (2), 144-156. 
[25] Richard, J.C. (2001). Curriculum development in language teaching. Cambridge: Cambridge University Press.

[26] Sample, G. M. (2015). Authentic materials: A Motivational Tool for EFL Classroom? Education and Linguistic Research. Vol. $1 \mathrm{~N}^{\circ} 2$.

[27] Sarapli, O. (2011). The Use of authentic Materials in the second Language Classroom. Advantages and disadvantages, Retrieved from http://dergiler.ankara.edu/tr/dergiler/27/1832/ 19277.pdf

[28] Schmitt, N. (2000). Vocabulary in language teaching. Cambridge, UK: Cambridge University Press.

[29] Scrivener, J. (1996).”ARC: A Descriptive Model for Classroom Work on Language". In: Willis, J. and Willis, D. (Eds) Challenge and Changein Language Teaching (Oxford: Macmillan Education, 79-92).

[30] Stern, H. (1981).Communicative language teaching and learning: Toward a synthesis. In J.E. Alatis, H. B. Altman. \& P. M. Alatis (Eds). The Second Language classroom: Directions for the 1980s (pp. 131-148). New-York: Oxford University Press.

[31] Sweet, H. (1899). The practical study of languages. London: Oxford University Press.

[32] Thanajaro, M. (2000). Using authentic materials to develop listening comprehension in the English as a foreign language classroom. Unpublished doctoral dissertation, Virginia Polytechnic Institute and State University, Blacksburg, Virginia.

[33] Wang, Y. \& Sachs, G. T. (2011). Comprehensible input through extensive reading: Problems in English language teaching in China. The Asian EFL Journal, 53, 61 -71.

[34] White, R. V. \& Gunstone, R. (1992). Probing Understanding. London: The Flamer Press.

[35] Young, D. (1999). Linguistic simplification of SL reading material: Effective instructional practice? The Modern Language Journal, 38(3), 350-366.

Citation: Estelle Bankole-Minaflinou. "Using Authentic Materials in EFL Classes in Benin for Communicative Competence" International Journal on Studies in English Language and Literature (IJSELL), vol 6, no. 10, 2018, pp. 8-19. doi:http://dx.doi.org/10.20431/2347-3134.0605004.

Copyright: (C) 2018 Authors. This is an open-access article distributed under the terms of the Creative Commons Attribution License, which permits unrestricted use, distribution, and reproduction in any medium, provided the original author and source are credited. 